\title{
Backstepping Terminal Sliding Mode MPPT Controller for Photovoltaic Systems
}

\author{
Khalissa Behih \\ Department of Electrical Engineering \\ LSI Laboratory \\ Ferhat Abbas Sétif 1 University \\ Sétif, Algeria \\ khalissabehih@univ-setif.dz
}

\author{
Hadjira Attoui \\ Department of Electrical Engineering \\ QUERE Laboratory \\ Ferhat Abbas Sétif 1 University \\ Sétif, Algeria \\ attoui_hadjira@univ-setif.dz
}

\begin{abstract}
In this paper, a new Maximum Power Point Tracking (MPPT) control for a Photovoltaic (PV) system is developed based on both backstepping and terminal sliding mode approaches. This system is composed of a solar array, a DC/DC boost converter, an MPPT controller, and an output load. The Backstepping Terminal Sliding Mode Controller (BTSMC) is used via a DC-DC boost converter to achieve maximum power output. The stability of the closed-loop system is guaranteed using the Lyapunov method. This novel approach provides good transient response, low tracking error, and very fast reaction against solar radiation and $\mathrm{PV}$ cell temperature variations. Furthermore, chattering, which constitutes the main disadvantage of the classic sliding mode technique is eliminated. To show the effectiveness and robustness of the proposed control, different simulations under different atmospheric conditions are conducted in Matlab/Simulink.
\end{abstract}

Keywords-backstepping; terminal sliding mode control; Lyapunov stability; maximum power point tracking; photovoltaic system

\section{INTRODUCTION}

Renewable energy sources are nowadays an important part of power generation. Photovoltaic (PV) generation is one of the most promising renewable sources since it exhibits many merits such as availability, cleanness, little maintenance, and no noise pollution. However, all PV systems have two problems: very low electric-power generation efficiency, especially under low-irradiation states and the interdependence of the amount of the electric power generated by solar arrays and the weather conditions. Load mismatch can occur under these weather varying conditions and maximum power may not be extracted and delivered to the load. This issue constitutes the so-called Maximum Power Point Tracking (MPPT) problem [1-4]. Many methods have been developed to determine the Maximum Power Point (MPP) under varying conditions [5-7]. Some of them are based on the well-known principle of perturb and observe $(\mathrm{P} \& \mathrm{O})[8]$, others are based on sliding mode control [9-12], on artificial neural networks, or on fuzzy logic algorithms [1, 2, 7]. In [12-14], Maximum Power Voltage (MPV) based approaches are developed using a two-loop MPPT control scheme. The first loop is to determine the MPV reference of the PV array and the second loop is to regulate the
PV array voltage to the reference voltage. The procedure repeats the MPV reference searching and the PV voltage tracking until maximum power is reached. To track MPP more efficiently a hybrid method consisting of two loops is proposed in [15]. In the first loop, the MPP is estimated using an incremental conductance method, and in the second loop a terminal sliding mode controller is developed to drive the system to the searched reference MPP. Authors in [16] proposed the use of backstepping sliding mode control for the second loop. The backstepping sliding mode control law is based on the asymptotic stability analysis whilst the system trajectories evolve to a specified attractor reaching the equilibrium in an infinite time. Many authors have proposed an alternative way to get a finite time convergence based on terminal attractor techniques [15-18], providing high-precision performance besides disturbance attenuation. Moreover, chattering in BSMC remains the problem that has to be overcome.

In order to avoid chattering, the major disadvantage in the sliding mode methodology, various methods have been proposed. One of them consists in replacing the sign function by a continuous approximation in the vicinity of the sliding surface. Saturation function or sigmoid function was used in fuzzy logic to build the transition band [9,21, 22]. The authors of [22] proposed to vary the sliding gain using a fuzzy system which adjusts the distance between the system and the sliding surface. Thus, its value decreases as the system state approaches the sliding surface. However, the ultimate accuracy and robustness of the sliding mode are partially lost.

In this paper, a Backstepping Terminal Sliding Mode Controller (BTSMC) is developed for MPPT. By using a $\mathrm{DC} / \mathrm{DC}$ boost converter in the power control circuit, the BTSMC is proposed to drive the system to the MPV reference in the second loop. Using this approach, finite time convergence of the error is guaranteed and the chattering effect is eliminated without losing robustness.

\section{PV SYSTEM MODELING}

A DC-DC boost converter constituting the heart of the MPPT is inserted between the PV module and its load to achieve optimum power transfer, as can be seen in Figure1. 


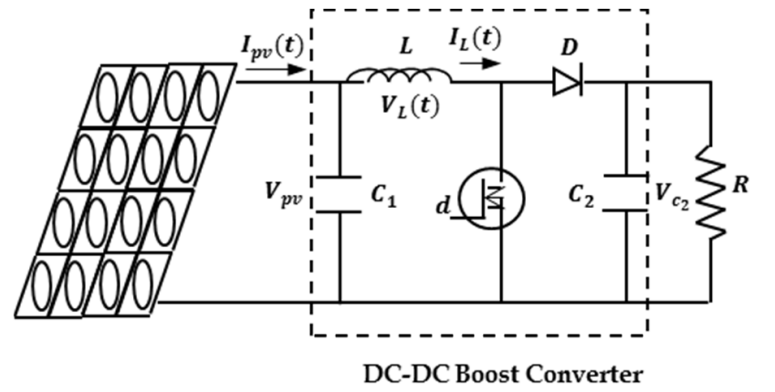

Fig. 1. Structure of the PV system.

The converter is used to regulate the PV module output voltage $V_{p v}$ in order to extract as much power as possible from the PV module. Referring to [15], the dynamics of the boost converter are given by:

$$
\left\{\begin{aligned}
\frac{d V_{p v}}{d t}= & \frac{1}{C_{1}}\left(I_{p v}-I_{L}\right) \\
\frac{d I_{L}}{d t}= & \frac{1}{L} V_{p v}-\frac{R_{C}(1-d)}{L\left(1+\frac{R_{c}}{R}\right)} I_{L} \\
& +\frac{(1-d)}{L}\left(\frac{R_{c}}{R_{c}+R}-1\right) V_{C_{2}}-\frac{V_{D}(1-d)}{L} \\
\frac{d V_{C_{2}}}{d t}= & \frac{(1-d)}{C_{2}\left(1+\frac{R_{c}}{R}\right)} I_{L}-\frac{1}{C_{2}\left(R_{c}+R\right)} V_{C_{2}}
\end{aligned}\right.
$$

where the three states variables $V_{p v}, I_{L}$ and $V_{C 2}$ are respectively the output voltage of the PV module, the inductor current and the voltage of the capacitor $C_{2}$ (i.e. the voltage across the load). $V_{D}$ is the forward voltage of the power diode, $d$ is the duty ratio of the PWM control input signal, and $R$ is the resistive load.

By taking $x(t)=\left[\begin{array}{lll}V_{p v}(t) & I_{L}(t) & V_{C_{2}}(t)\end{array}\right]^{T}$, the set of equations in (1) can be written in the following form [15]:

$$
\left\{\begin{array}{l}
\frac{d V_{p v}}{d t}=\frac{1}{C_{1}}\left(I_{p v}-I_{L}\right) \\
\frac{d I_{L}}{d t}=f_{1}(x)+g_{1}(x) d \\
\frac{d V_{C_{2}}}{d t}=f_{2}(x)+g_{2}(x) d
\end{array}\right.
$$

where:

$$
f_{1}(x)=\frac{1}{L} V_{p v}-\frac{R_{C}}{L\left(1+\frac{R_{c}}{R}\right)} I_{L}+\frac{1}{L}\left(\frac{R_{c}}{R_{c}+R}-1\right) V_{C_{2}}-\frac{V_{D}}{L}
$$

$$
\begin{gathered}
f_{2}(x)=\frac{1}{C_{2}\left(1+\frac{R_{c}}{R}\right)} I_{L}-\frac{1}{C_{2}\left(R_{c}+R\right)} V_{C_{2}} \\
g_{1}(x)=\frac{R_{c}}{L\left(1+\frac{R_{c}}{R}\right)} I_{L}-\frac{1}{L}\left(\frac{R_{c}}{R_{c}+R}-1\right) V_{C_{2}}+\frac{V_{D}}{L} \\
g_{2}(x)=-\frac{1}{L} \frac{1}{C_{2}\left(1+\frac{R_{c}}{R}\right)} I_{L}
\end{gathered}
$$

III. DESIGN OF THE BACKSTEPPING TERMINAL SLIDING MODE MPPT CONTROLLER

The overall control structure is illustrated in Figure 2. Here, $i_{p v}$ and $V_{p v}$ are measured from the PV array and transmitted to the MPP searching algorithm, which generates the reference maximum power voltage $V_{\text {ref }}$. Then, the reference voltage is given to the MPV based BTSM controller for maximum power tracking.

\section{A. MPP Searching Algorithm}

To seek the MPP voltage $V_{r e f}$, we use an incremental conductance method $[1,15]$. The power slope $d P_{p v} / d V_{p v}$ can be expressed as:

$$
\frac{d P_{p v}}{d V_{p v}}=I_{p v}+V_{p v} \frac{d I_{p v}}{d V_{p v}}
$$

When the power slope $\frac{d P_{p v}}{d V_{p v}}=0$, i.e $\frac{d I_{p v}}{d V_{p v}}=-\frac{I_{p v}}{V_{p v}}$, the PV system operates at maximum power generation. Therefore, the update law for $V_{\text {ref }}$ is given by the following rules $[1,15]$ :

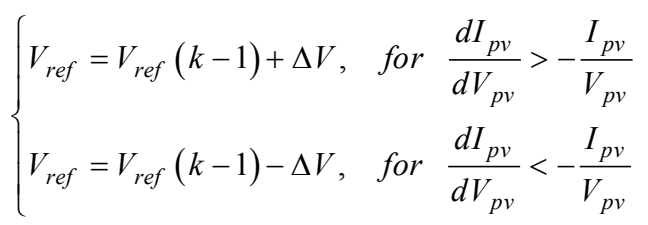

\section{B. Backstepping Terminal Sliding Model Controller}

The backstepping terminal sliding mode controller is designed to extract maximum power from a PV panel. The objective of the controller is to let the panel PV voltage $V_{p v}$ track the reference maximum power voltage $V_{\text {ref }}$ by acting on the duty cycle $d(t)$ of the boost converter switch. The recursive nature of the proposed control design is similar to the standard backstepping methodology. However, the proposed control design uses backstepping to design controllers with a terminal sliding surface at the last step [22-23]. The design proceeds as follows:

For the first step we consider a zero-order sliding surface:

$$
e_{1}=x_{1}-V_{\text {ref }}
$$

Considering an auxiliary tracking error variable: 


$$
e_{2}=\dot{e}_{1}+\alpha_{1}
$$

Let the first Lyapunov function candidate is:

$$
V_{1}=\frac{1}{2} e_{1}^{2}
$$

The time derivation of (7) is given by:

$$
\begin{aligned}
\dot{V}_{1} & =e_{1} \dot{e}_{1} \\
& =e_{1}\left(e_{2}-\alpha_{1}\right) \\
& =-\lambda_{1} e_{1}^{2}+e_{1} e_{2}
\end{aligned}
$$

The stabilization of $e_{1}$ can be obtained by introducing a new virtual control $\alpha_{1}$, such that:

$$
\alpha_{1}=\lambda_{1} e_{1}, \quad \lambda_{1}>0
$$

where $\lambda_{1}$ is a positive feedback gain, such that $\alpha_{1}$ can be chosen in order to eliminate the nonlinearity and getting $\dot{V}_{1}(x)<0$.

Equation (8) shows that, if the designed control law makes $e_{2}$ converge, then $\dot{V}_{1}(x)<0$ which guarantees global stability. In order to make $e_{2}$ converge in finite time and improve the convergence rate and the steady-state tracking accuracy of the system, the higher-order non-singular terminal sliding mode surface is designed for $e_{2}$ as follows:

$$
s=e_{2}+\gamma \dot{e}_{2}{ }^{\frac{p}{q}}, \quad 1<p / q<2, \gamma>0
$$

where $\gamma>0$ is a positive constant that contributes to force the error $e_{2}$ to converge to zero while $p$ and $q$ are positive impair constants such that $1<p / q<2$. This last inequality must be enforced to avoid the inherent singularity in such types of control. The surface selected in (10) is called Nonsingular Terminal Sliding Mode (NTSM). It is used to realize a secondorder SMC, enabling to have $s=\dot{s}=\ddot{s}=0$, often called higherorder sliding mode. If the system converges on $t_{r}, s$ converges to zero, which means $s(t)=0, t \geq t_{r}$ then from (10), it can be shown that $e_{2}$ and $\dot{e}_{2}$ will converge to zero in finite time, given by:

$$
t_{s}=t_{r}+\gamma^{p / q} \frac{p}{(p-q)}\left|e_{2}\left(t_{r}\right)\right|^{\frac{p-q}{p}}
$$

The system will remain on the second-order sliding mode $\left(e_{2}=\dot{e}_{2}=0\right)$, according to (11), and by selecting the parameters $p, q$, and $\gamma$ one can adjust the convergence speed of $e_{2}$.

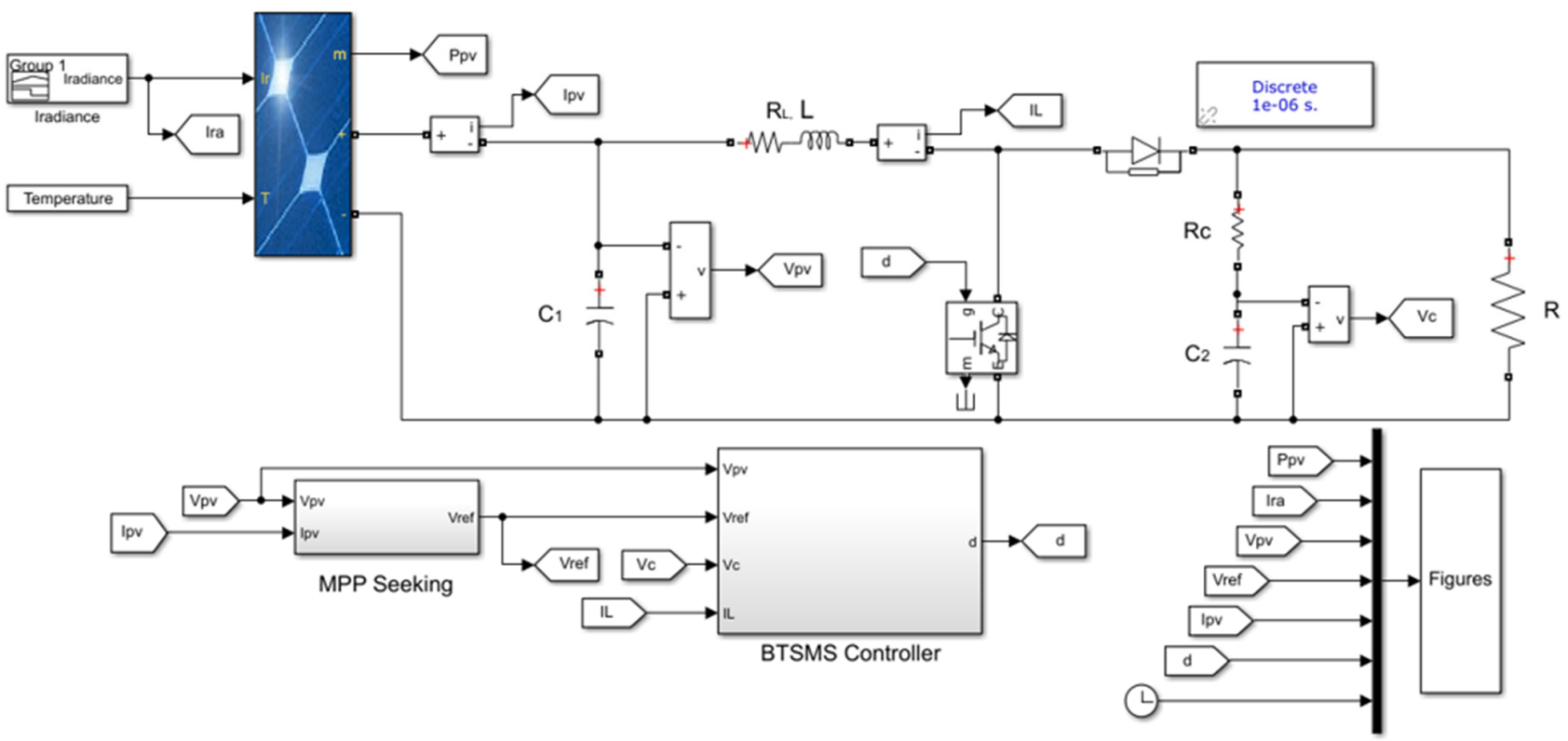

Fig. 2. Simulink PV system model.

\section{Stability and Robustness Analysis}

The stability and robustness issues of the controller are addressed here by using Lyapunov stability theory as follows:

The augmented Lyapunov function is given by:

$$
V_{2}=\frac{1}{2} s^{2}
$$

The time derivative of $V_{2}(s)$ is then:

$$
\dot{V}_{2}=s \dot{s}
$$




$$
\begin{aligned}
\dot{V}_{2} & =s\left[\dot{e}_{2}+\gamma \frac{p}{q} \dot{e}_{2}^{\left(\frac{p}{q}-1\right)} \ddot{e}_{2}\right] \\
& =s \gamma \frac{p}{q} \dot{e}_{2}\left(\frac{p}{q}-1\right)\left[\ddot{e}_{2}+\frac{1}{\gamma} \frac{q}{p} \dot{e}_{2}\left(2-\frac{p}{q}\right)\right]
\end{aligned}
$$

with:

$$
\begin{aligned}
& \dot{e}_{2}=\ddot{e}_{1}+\dot{\alpha}_{1} \\
& =\ddot{V}_{p v}-\ddot{V}_{r e f}+\dot{\alpha}_{1} \\
& \dot{V}_{2}=s\left[\dot{e}_{2}+\gamma \frac{p}{q} \dot{e}_{2}^{\left(\frac{p}{q}-1\right)} \ddot{e}_{2}\right] \\
& =s \gamma \frac{p}{q} \dot{e}_{2}{ }^{\left(\frac{p}{q}-1\right)}\left[\ddot{e}_{2}+\frac{1}{\gamma} \frac{q}{p} \dot{e}_{2}\left(2-\frac{p}{q}\right)\right]
\end{aligned}
$$

To satisfy the Lyapunov stability condition, the input signal control is designed as in (17):

$$
d(t)=\frac{1}{g_{1}(x)}\left[d_{1}(t)+d_{2}(t)\right], g_{1}(x) \neq 0
$$

where

$$
d_{1}(t)=-f_{1}(x)+\dot{I}_{p v}-C_{1} \ddot{V}_{r e f}+C_{1} \dot{\alpha}_{1}
$$

and

$$
d_{2}(t)=C_{1}\left[\int_{0}^{t}\left[\frac{1}{\gamma} \frac{q}{p} \dot{e}_{2}{ }^{\left(2-\frac{p}{q}\right)}+\eta \operatorname{sign}(s)\right] d t\right]
$$

Equation (14) can therefore be developed to give:

$$
\dot{V}_{2}=-\gamma \frac{p}{q} \dot{e}_{2}\left(\frac{p}{q}-1\right) . \eta|s|
$$

If $s \neq 0$, as $p$ and $q$ are odd and $1<p / q<2$, then $\dot{e}_{2}{ }^{p / q-1} \geq 0$, which means $\dot{V}_{2} \leq 0$. If $s \neq 0$, we will consider the two following conditions:

- If $z_{n} \neq 0$, then $\dot{V}_{2}=-\gamma \frac{p}{q} \dot{e}_{2}{ }^{\left(\frac{p}{q}-1\right)} . \eta|s|<0$ and

- If $\dot{z}_{n}=0, z_{n} \neq 0$ then $\dot{V}_{2}=0$ cannot be kept continuously.

Thus, according to Lyapunov stability theory, the system can reach the manifold in finite time, for $e_{2}$ converges to zero in finite time.

\section{SimUlation RESUlTS}

The Simulink PV system model shown in Figure 2 was selected to assess the performance and the effectiveness of the proposed BTSMC controller. Fixed-step type and ode4 (Runge Kutta) solver were the Simulink solver selection parameters. The specification parameters for PV power generation are given in Table I. The parameters of the boost converter used are: $L=12 \mathrm{mH}, R_{L}=0.15 \Omega, R_{C}=39.6 \Omega, C_{2}=1000 \mu \mathrm{F}, R=25 \Omega$, and $V_{D}=0.82 \mathrm{~V}$. The controller parameters used are: $\gamma=50, \eta=0.01$, $p=7, q=5$. In this section, we present the simulation results when applying the Backstepping Terminal Sliding Mode control law.

TABLE I. ELECTRICAL SPECIFICATIONS OF THE KC200GH-2P PV MODULE

\begin{tabular}{|c|c|}
\hline Parameter & Value \\
\hline Maximum power $P_{m p p}$ & $200 \mathrm{~W}$ \\
\hline Short circuit current $I_{S c r}$ & $8.21 \mathrm{~A}$ \\
\hline Open circuit voltage $V_{O C}$ & $32.9 \mathrm{~V}$ \\
\hline Voltage at maximum power point $V_{m p p}$ & $26.3 \mathrm{~V}$ \\
\hline Current at maximum power point $I_{m p p}$ & $7.61 \mathrm{~A}$ \\
\hline P-N junction characteristic factor $A$ & 1.8 \\
\hline
\end{tabular}

\section{A. Simulation Results with Standard Operating Conditions}

The simulation results with standard operating conditions $\left(S=1000 \mathrm{~W} / \mathrm{m}^{2}, T=25^{\circ} \mathrm{C}\right)$ are shown in Figures 3-6. From the obtained results, it is clearly noted that $V_{p v}$ reaches quickly the desired set point $V_{\text {ref. }}$.

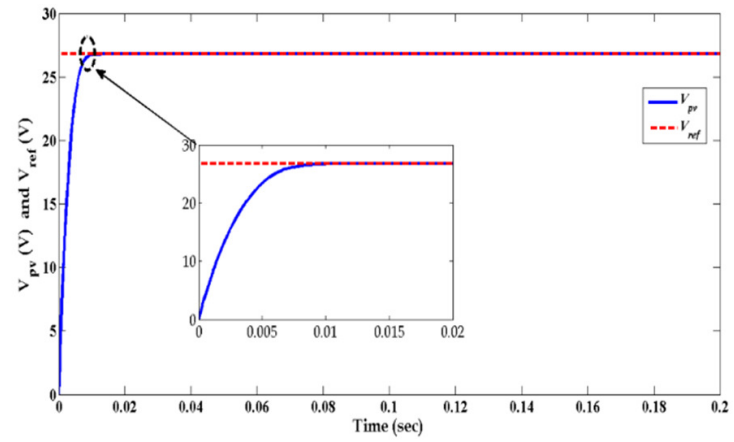

Fig. 3. Evolution of $V_{p v}$ and $V_{r e f}$.

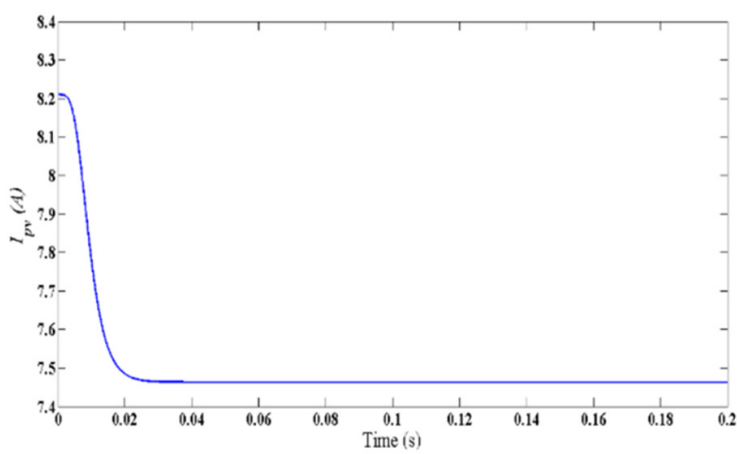

Fig. 4. Evolution of $I_{p v}$. 


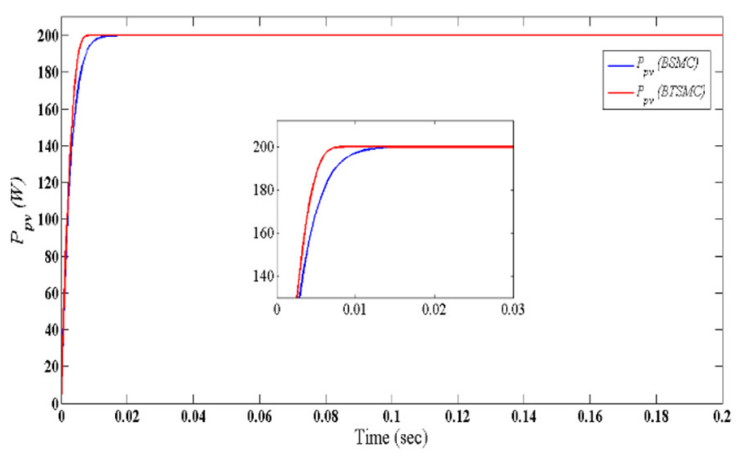

Fig. 5. Evolution of $P_{p v}$.

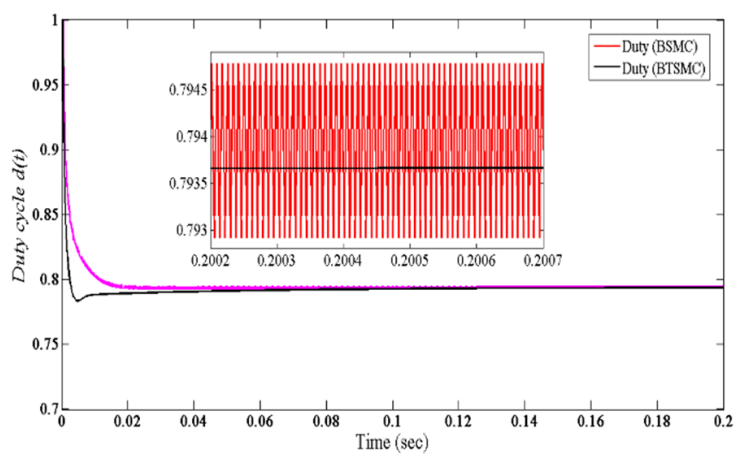

Fig. 6. Evolution of duty cycle $d(t)$.

The $P_{p v}$ achieves maximum power in a settling time of $0.008 \mathrm{~s}$. Moreover, it can be deduced that the proposed approach presents good transient response, low tracking error, and a very fast system reaction against set point change. Figures 5-6 present a comparative study between the proposed controller and the BSMC. When comparing these results, it is obvious that the proposed method provides faster responses while eliminating the phenomenon of chattering.

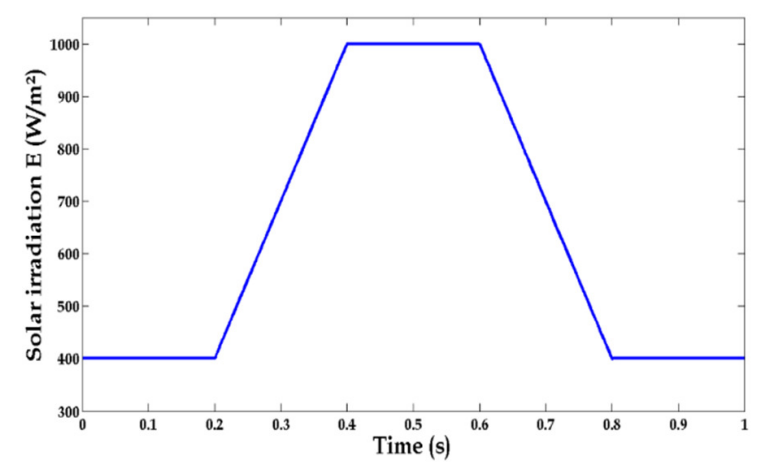

Fig. 7. Solar irradiation variation.

\section{B. Simulation Results under Solar Irradiation Rariation}

It is known that meteorological parameters, especially the temperature, do not remain constant all day long, but change significantly. It is then worth investigating the influence of the daily average temperature variation on the performance of the optimized system. In order to evaluate the effect of changing irradiation conditions, an irradiation ramp change was used as shown in Figure 7. The temperature is considered constant with a value of $25^{\circ} \mathrm{C}$ during the simulation tests. The performances including $V_{p v}, I_{p v}, P_{p v}$, and duty cycle are given in Figures 8-11.

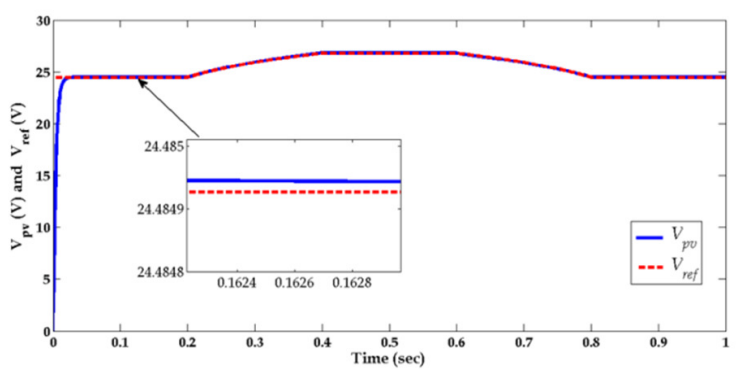

Fig. 8. Evolution of $V_{p v}$ and $V_{\text {ref. }}$

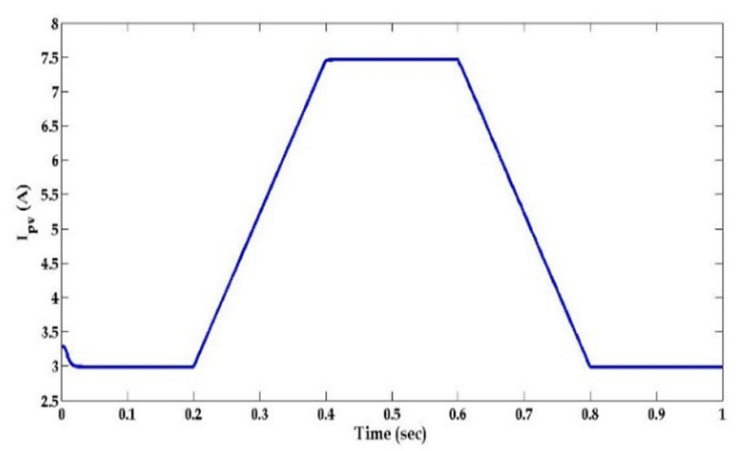

Fig. 9. Evolution of $I_{p v}$.

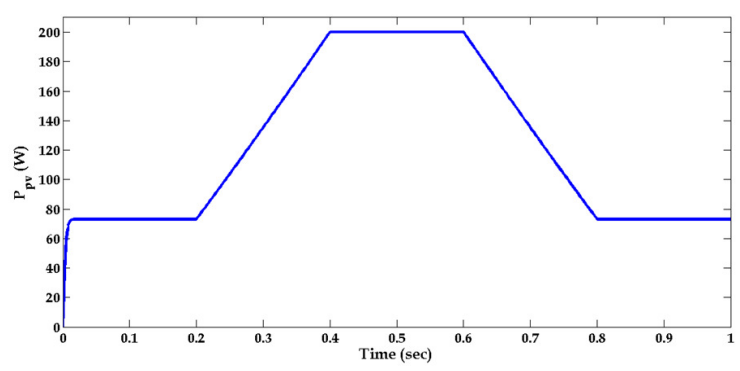

Fig. 10. Evolution of $P_{p v}$.

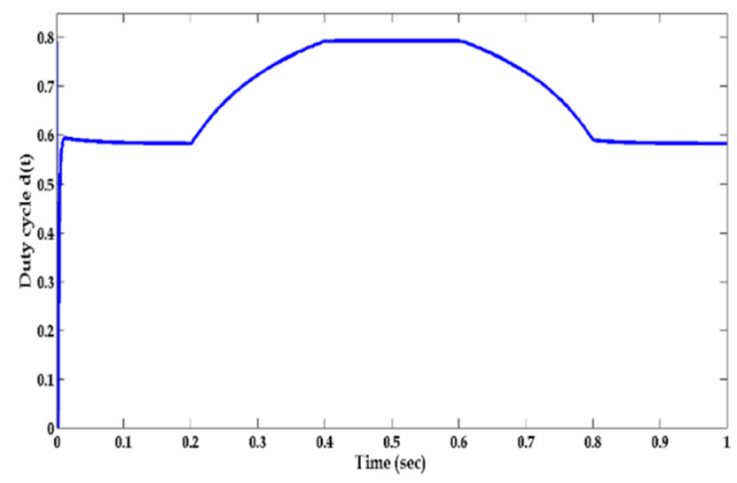

Fig. 11. Evolution of duty cycle $d(t)$. 
As shown in Figures 8-11, when the irradiance level changes, the MPPT controller can quickly track the MPP. It can be seen from the results that the proposed MPPT controller follows the direction of the MPP perfectly.

\section{Simulation Results under Temperature Variations}

Simulations were carried out to evaluate the effect of changing temperature (Figure 12). The solar irradiation is considered constant with a value of $1000 \mathrm{~W} / \mathrm{m}^{2}$. The performances including $V_{p v}, I_{p v}, P_{p v}$, and duty cycle are given in Figures 13-16.

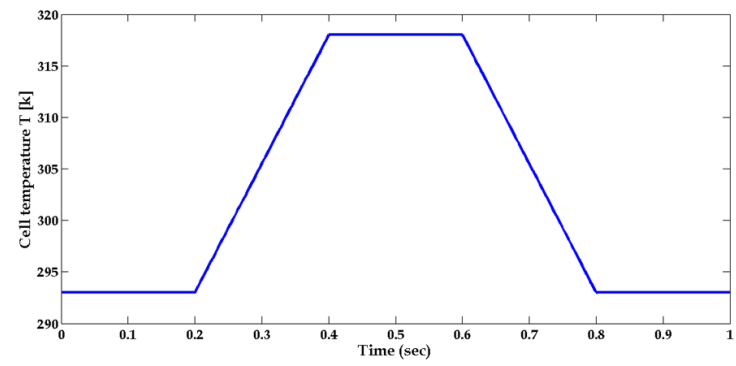

Fig. 12. Temperature variation.

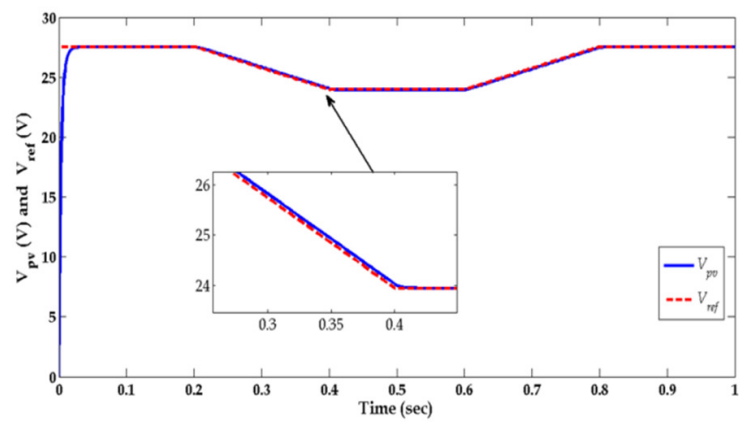

Fig. 13. Evolution of $V_{p v}$ and $V_{r e f}$.

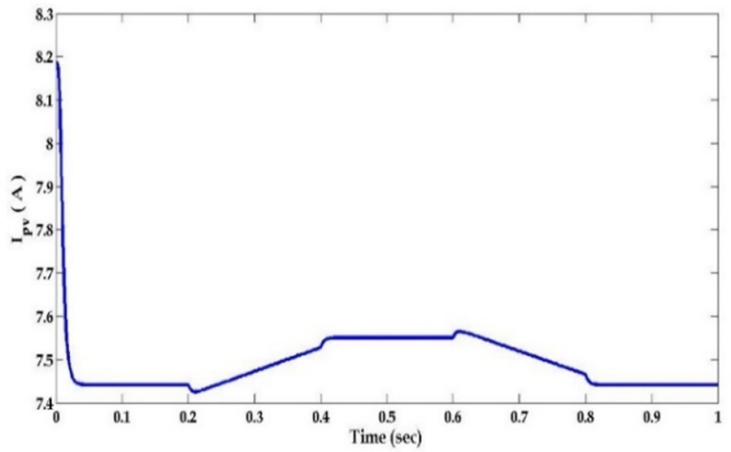

Fig. 14. Evolution of $I_{p v}$.

It can be seen in Figures 13-16 that when the temperature changes, the MPPT controller can quickly track the MPP. The proposed MPPT controller provides a good performance in all simulation tests. Figure 17 shows that the trace of the operating point stays close to the MPPs during the simulation.

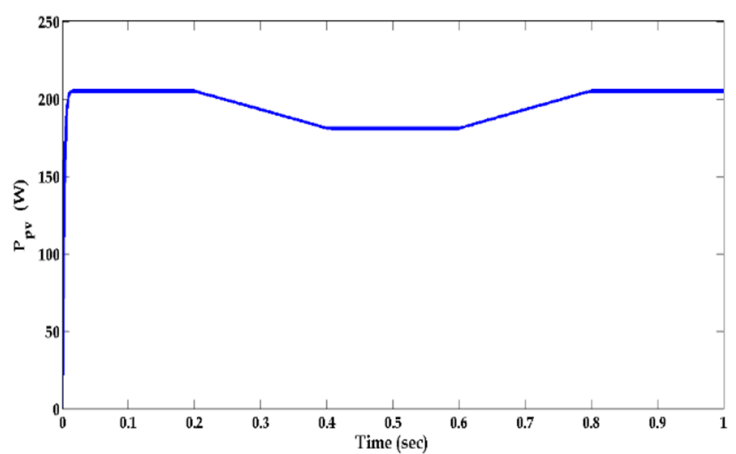

Fig. 15. Evolution of $P_{p v}$.

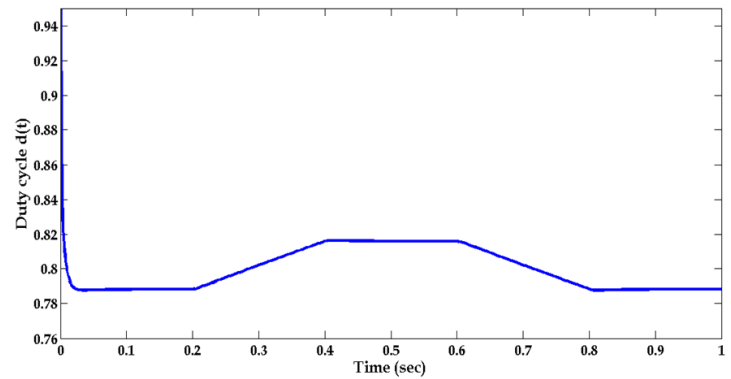

Fig. 16. Evolution of duty cycle $d(t)$.

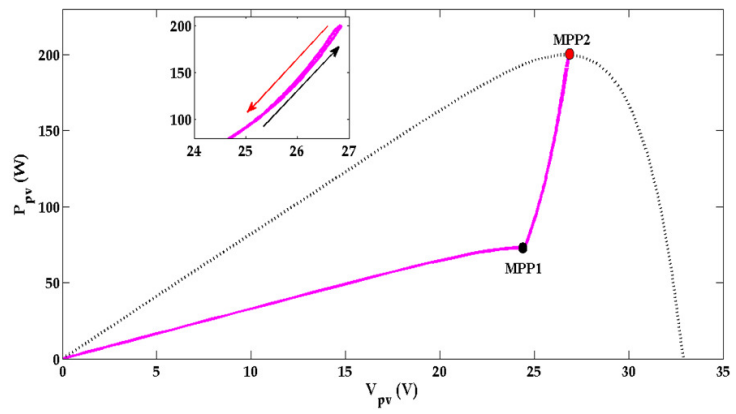

Fig. 17. $V_{p v}-P_{p v}$ characteristics under solar irradiation variation.

\section{Simulation Results under Load Variation}

Considering load change from $25 \Omega$ to $80 \Omega$ under the same irradiance and temperature, the corresponding results are shown in Figures 18-20. It can be easily concluded that the proposed controller achieves strong robustness and has satisfactory response under these types of disturbance.

In all the simulation results, the proposed BTSMC provides a good performance. The proposed MPPT controller follows the direction of the MPP perfectly and in finite time. Furthermore, the elimination of the chattering problem permits the smoothness of the control law.

\section{CONCLUSION}

In this study, a backstepping sliding mode control scheme for MPPT of a PV system has been developed, which integrates the backstepping methodology and the terminal sliding mode 
control strategy. The combined strategies proved to have the advantages of both the terminal sliding mode and the backstepping approach. The parameters of the proposed controller are adjusted using adaptation laws, based on the Lyapunov synthesis in order to ensure, in the presence of external disturbances, the stability of the closed-loop system and the tracking performance is achieved in finite time.

The objective of the study was accomplished. Low tracking error, very fast system reaction against solar radiation change, and good transition response without overshoot was obtained. Moreover, it has been shown that the chattering phenomenon appearing in the classical backstepping sliding mode control was reduced. Besides, the proposed algorithm provides a shorter rise-time than the backstepping sliding mode control. Future work will include the implementation of the algorithm on a PV system using dSPACE1104 including a partial shading influence study.

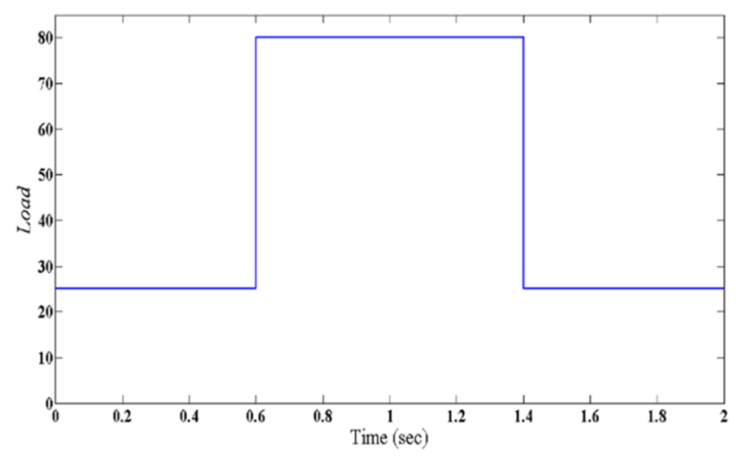

Fig. 18. Charge variation.

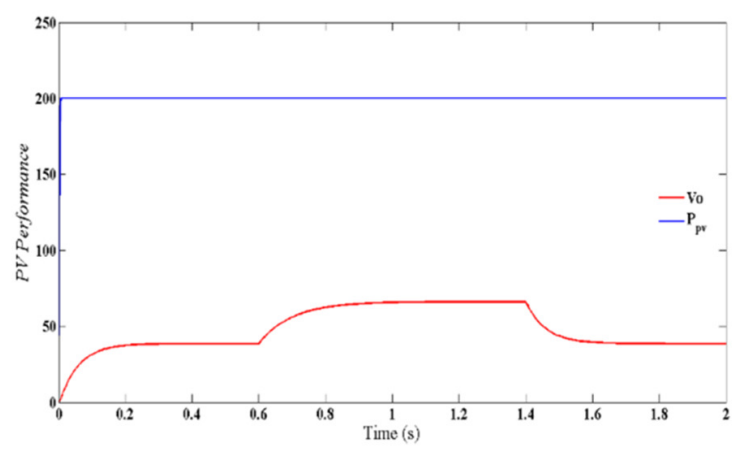

Fig. 19. PV performance.

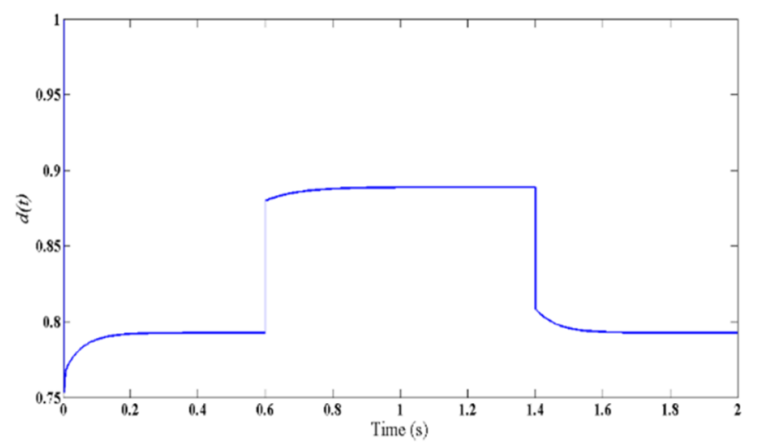

Fig. 20. Evolution of duty cycle.

\section{REFERENCES}

1] M. Y. Allani, D. Mezghani, F. Tadeo, and A. Mami, "FPGA Implementation of a Robust MPPT of a Photovoltaic System Using a Fuzzy Logic Controller Based on Incremental and Conductance Algorithm," Engineering, Technology \& Applied Science Research, vol. 9, no. 4, pp. 4322-4328, Aug. 2019, https://doi.org/10.48084/etasr.2771.

[2] A. Elgharbi, D. Mezghani, and A. Mami, "Intelligent Control of a Photovoltaic Pumping System," Engineering, Technology \& Applied Science Research, vol. 9, no. 5, pp. 4689-4694, Oct. 2019, https://doi.org/10.48084/etasr.2982.

[3] M. Aly and H. Rezk, "A Differential Evolution-Based Optimized Fuzzy Logic MPPT Method for Enhancing the Maximum Power Extraction of Proton Exchange Membrane Fuel Cells," IEEE Access, vol. 8, pp. 172219-172232, 2020, https://doi.org/10.1109/ACCESS.2020.3025222.

[4] J. E. Hernández-Díez, C. F. Méndez-Barrios, S. I. Niculescu, and E. Bárcenas-Bárcenas, "A current sensorless delay-based control scheme for MPPT-boost converters in photovoltaic systems," IEEE Access, vol. 8 , pp. 174449-174462, 2020, https://doi.org/10.1109/ACCESS. 2020.3024566 .

[5] J. Wang, C. Wang, S. jia, S. Xiang, and X. Shan, "Photovoltaic power MPPT controller based on fuzzy-backstepping method," in 20198 th International Symposium on Next Generation Electronics (ISNE), Zhengzhou, China, Oct. 2019, pp. 1-3, https://doi.org/10.1109/ ISNE.2019.8896680.

[6] O. Abdel-Rahim and H. Wang, "A new high gain DC-DC converter with model-predictive-control based MPPT technique for photovoltaic systems," CPSS Transactions on Power Electronics and Applications, vol. 5, no. 2, pp. 191-200, Jun. 2020, https://doi.org/10.24295/ CPSSTPEA.2020.00016

[7] K. Y. Yap, C. R. Sarimuthu, and J. M.-Y. Lim, "Artificial Intelligence Based MPPT Techniques for Solar Power System: A review," Journal of Modern Power Systems and Clean Energy, vol. 8, no. 6, pp. 1043-1059, Nov. 2020, https://doi.org/10.35833/MPCE.2020.000159.

[8] Z. R. Labidi, H. Schulte, and A. Mami, "A Systematic Controller Design for a Photovoltaic Generator with Boost Converter Using Integral State Feedback Control," Engineering, Technology \& Applied Science Research, vol. 9, no. 2, pp. 4030-4036, Apr. 2019, https://doi.org/ 10.48084/etasr.2687.

[9] Y. Zhang, Q. Zhang, J. Zhang, and Y. Wang, "Sliding Mode Control for Fuzzy Singular Systems With Time Delay Based on Vector Integral Sliding Mode Surface," IEEE Transactions on Fuzzy Systems, vol. 28, no. 4, pp. 768-782, Apr. 2020, https://doi.org/10.1109/TFUZZ. 2019.2916049.

[10] A. Bag, B. Subudhi, and P. K. Ray, "A combined reinforcement learning and sliding mode control scheme for grid integration of a PV system," CSEE Journal of Power and Energy Systems, vol. 5, no. 4, pp. 498-506, Dec. 2019, https://doi.org/10.17775/CSEEJPES.2017.01000.

[11] Z. Meng, W. Shao, J. Tang, and H. Zhou, "Sliding-mode control based on index control law for MPPT in photovoltaic systems," CES Transactions on Electrical Machines and Systems, vol. 2, no. 3, pp. 303311, Sep. 2018, https://doi.org/10.30941/CESTEMS.2018.00038.

[12] I.-S. Kim, "Robust maximum power point tracker using sliding mode controller for the three-phase grid-connected photovoltaic system," Solar Energy, vol. 81, no. 3, pp. 405-414, Mar. 2007, https://doi.org/10.1016/ j.solener.2006.04.005.

[13] E. Koutroulis, K. Kalaitzakis, and N. C. Voulgaris, "Development of a microcontroller-based, photovoltaic maximum power point tracking control system," IEEE Transactions on Power Electronics, vol. 16, no. 1, pp. 46-54, Jan. 2001, https://doi.org/10.1109/63.903988.

[14] M. Veerachary, T. Senjyu, and K. Uezato, "Neural-network-based maximum-power-point tracking of coupled-inductor interleaved-boostconverter-supplied PV system using fuzzy controller," IEEE Transactions on Industrial Electronics, vol. 50, no. 4, pp. 749-758, Aug. 2003, https://doi.org/10.1109/TIE.2003.814762.

[15] C.-S. Chiu, Y.-L. Ouyang, and C.-Y. Ku, "Terminal sliding mode control for maximum power point tracking of photovoltaic power generation systems," Solar Energy, vol. 86, no. 10, pp. 2986-2995, Oct. 2012, https://doi.org/10.1016/j.solener.2012.07.008. 
[16] K. Dahech, M. Allouche, T. Damak, and F. Tadeo, "Backstepping sliding mode control for maximum power point tracking of a photovoltaic system," Electric Power Systems Research, vol. 143, pp. 182-188, Feb. 2017, https://doi.org/10.1016/j.epsr.2016.10.043.

[17] N. Zerroug, M. N. Harmas, S. Benaggoune, Z. Bouchama, and K. Zehar, "DSP-based implementation of fast terminal synergetic control for a DC-DC Buck converter," Journal of the Franklin Institute, vol. 355, no. 5, pp. 2329-2343, Mar. 2018, https://doi.org/10.1016/j.jfranklin. 2018.01.004.

[18] R. Ma, H. Zhang, M. Yuan, B. Liang, Y. Li, and Y. Huangfu, "Chattering Suppression Fast Terminal Sliding Mode Control for Aircraft EMA Braking System," IEEE Transactions on Transportation Electrification, 2021, https://doi.org/10.1109/TTE.2021.3054510.

[19] K. Behih, K. Benmahammed, Z. Bouchama, and M. N. Harmas, "RealTime Investigation of an Adaptive Fuzzy Synergetic Controller for a DC-DC Buck Converter," Engineering, Technology \& Applied Science Research, vol. 9, no. 6, pp. 4984-4989, Dec. 2019, https://doi.org/10. 48084/etasr.3172.

[20] Z. B. Duranay, H. Guldemir, and S. Tuncer, "Fuzzy Sliding Mode Control of DC-DC Boost Converter," Engineering, Technology \& Applied Science Research, vol. 8, no. 3, pp. 3054-3059, Jun. 2018, https://doi.org/10.48084/etasr.2116.

[21] S. Latreche and S. Benaggoune, "Robust Wheel Slip for Vehicle Antilock Braking System with Fuzzy Sliding Mode Controller (FSMC)," Engineering, Technology \& Applied Science Research, vol. 10, no. 5, pp. 6368-6373, Oct. 2020, https://doi.org/10.48084/etasr.3830.

[22] T. L. Nguyen, T. H. Vo, and N. D. Le, "Backstepping Control for Induction Motors with Input and Output Constrains," Engineering Technology \& Applied Science Research, vol. 10, no. 4, pp. 5998-6003, Aug. 2020, https://doi.org/10.48084/etasr.3680.

[23] B. K. Oubbati, M. Boutoubat, A. Rabhi, and M. Belkheiri, "Experiential Integral Backstepping Sliding Mode Controller to achieve the Maximum Power Point of a PV system," Control Engineering Practice, vol. 102, Sep. 2020, Art. no. 104570, https://doi.org/10.1016/j.conengprac. 2020.104570 . 